\title{
Isolation, identification and complete genome sequence analysis of a strain of foot-and-mouth disease virus serotype Asia1 from pigs in southwest of China
}

\author{
Xin Yang, Ying-shun Zhou, Hong-ning Wang ${ }^{*}$, Yi Zhang, Kun Wei and Ting Wang
}

\begin{abstract}
Backgroud: Foot-and-mouth disease virus (FMDV) serotype Asia1 generally infects cattle and sheep, while its infection of pigs is rarely reported. In 2005-2007, FMD outbreaks caused by Asia1 type occurred in many regions of China, as well as some parts of East Asia countries. During the outbreaks, there was not any report that pigs were found to be clinically infected.

Results: In this study, a strain of FMDV that isolated from pigs was identified as serotype Asia1, and designated as "Asia1/WHN/CHA/06". To investigate the genomic feature of the strain, complete genome of Asia1/WHN/CHA/06 was sequenced and compared with sequences of other FMDVs by phylogenetic and recombination analysis. The complete genome of Asia1/WHN/CHA/06 was 8161 nucleotides (nt) in length, and was closer to JS/CHA/05 than to all other strains. Potential recombination events associated with Asia1/WHN/CHA/06 were found between JS/ CHA/05 and HNK/CHA/05 strains with partial 3B and 3 C fragments.

Conclusion: This is the first report of the isolation and identification of a strain of FMDV type Asia1 from naturally infected pigs. The Asia1/WHN/CHA/06 strain may evolve from the recombination of JS/CHA/05 and HNK/CHA/05 strains.
\end{abstract}

\section{Background}

Foot-and-mouth Disease is a highly contagious and economically important disease of cloven-hoofed animals, predominantly for cattle, sheep, and pigs. The aetiological agent, foot-and-mouth disease virus, is classified as small icosahedral virus of the Aphthovirus group within the Picornaviridae family. There are seven immunologically distinct serotypes of the virus, namely types $\mathrm{O}, \mathrm{A}$, C, SAT1, SAT2, SAT3 and Asia1, and subtypes have also been found within some serotypes [1].

FMD serotype Asial has been epidemic in China for more than 50 years. This serotype usually infects cattle and sheep, and its infection of pigs is seldom reported

\footnotetext{
* Correspondence: whongning@163.com

School of Life science, Sichuan University, Animal Disease Prevention and Food Safety Key Laboratory of Sichuan Province," 985 Project" Science Innovative Platform for Resource and environment Protection of Southwestern, Key Laboratory of Bio-resources and Eco-environment, Ministry of Education, Chengdu, Sichuan, 610064, China
}

[2]. In 2005-2007, FMD outbreaks caused by Asia1 type occurred in many regions of China, as well as some parts of East Asia countries. During the outbreaks, there was not any report that pigs were found to be clinically infected [2].

FMDV has a single-stranded positive sense RNA genome of approximately $8.5 \mathrm{~kb}$ in length, including the 5 , untranslated region ( $\left.5^{\prime} \mathrm{UTR}\right)$, a large singe open reading frame (ORF), and the 3' untranslated region (3'UTR) $[3,4]$. The 5' UTR consists of a short (S) fragment, a poly $(\mathrm{C})$ tract, and a long fragment ( $\left.5^{\prime} \mathrm{LF}-\mathrm{UTR}\right)$, which contains three or four tandemly repeated pseudoknots (PKs) and an internal ribosome entry site (IRES) [5]. The ORF encodes a polyprotein that can be cleaved to form four structural proteins (VP4, VP2, VP3 and VP1) and 8 non-structural proteins $(\mathrm{L}, 2 \mathrm{~A}, 2 \mathrm{~B}, 2 \mathrm{C}, 3 \mathrm{~A}, 3 \mathrm{~B}, 3 \mathrm{C}$ and 3D) [5]. The VP1 protein plays an important role in virus attachment, protective immunity and serotype specificity, and nucleotide sequencing of this region has 
been extensively used for molecular epidemiology studies on FMD [6,7]. The G-H loop of the VP1 protein of FMDV spanning residues 134-158 contains conserved Arg-Gly-Asp (RGD) tripeptide, which is considered to be a ligand for cell-surface attachment [8]. In addition, FMDV 3A region has been implicated in virus virulence and host range, similar to the $3 \mathrm{~A}$ proteins of other picornaviruses [9]. The 3'UTR of about 90 residues with a poly (A) tail (35-100nt) at 3'-end is likely to be a site of interaction with viral and host proteins for RNA replication $[10,11]$.

This study, for the first time to our knowledge, described the isolation and identification of a strain of FMDV type Asia1 from pigs in China. To investigate the genomic feature of the strain and further understand its role in epidemiology of FMDV, the complete genome of the strain was sequenced and compared with sequences of other strains of FMDV Asia1 by phylogenetic and recombination analysis.

\section{Materials and methods}

\section{Sample collection and clinical samples treatment}

Three samples of ruptured vesicular fluids were collected from FMD-suspected pigs in a pig farm in southwest of China in 2006. The samples were transported from the collection site to diagnostic laboratory in 0.04 $\mathrm{M}$ phosphate buffer ( $\mathrm{pH} 7.2)$ with $50 \%$ glycerol at $4{ }^{\circ} \mathrm{C}$ and stored at $-20^{\circ} \mathrm{C}$ until tested.

\section{Virus isolation and identification}

Established cell layer of BHK-21 cells were inoculated with $0.2 \mathrm{ml}$ the three samples of vesicular fluids, respectively. The cell cultures would be examined for Cytopathic effects (CPE) for 48 hours. If CPE was formed, the cells would be collected for subsequent experiments. If no CPE was detected, the cells would be frozen and thawed, and used to inoculate fresh cultures of 0.2 $\mathrm{ml}$ and examined for CPE for another 48 hours. The infected BHK-21 monolayer cells were subjected to three freeze-thaw cycles to release the viral particles. The viral suspension was clarified from the cell debris by centrifugation at $800 \times \mathrm{g}$ for $10 \mathrm{~min}$ and stored at $-70^{\circ} \mathrm{C}$ for the following experiments.

The FMDV O, Asial and A type positive serums were chosen as antiserum in complement fixation test (CFT). The CFT was performed by adding $0.2 \mathrm{ml}$ virus sample, each of the 3 type of antiserum and complement in tubes, respectively. After incubating the mixtures at $37^{\circ}$ $\mathrm{C}$ for $1.5 \mathrm{~h}$, sensitized sheep erythrocytes was added to each tube, and the mixtures were incubated for $1 \mathrm{~h}$ at $37^{\circ} \mathrm{C}$. Degrees of hemolysis were determined by visual reading. The tests were set up in triplicate. Also, virus sample, antisera, complement, and erythrocytes controls were set up with each test.

\section{RNA extraction and RT-PCR}

The RNA was extracted from the infected cell culture supernatant by using RNeasy kit (Qiagen). The cDNA synthesis was carried out using Random primer $_{9}$ and Oligo $(\mathrm{dT})_{18}$, and Superscript $\Pi$ reverse transcriptase (Invitrogen). The cDNA fragments were amplified by PCR (Biorad) using LA Taq DNA polymerase (TaKaRa, Japan a) and seven pairs of primers (Table 1). The 5'RACE was performed using 5'-full RACE kit (TaKaRa, Japan) following the manufacturer's instructions. The cDNA fragment at the 3' UTR was amplified by the 3'rapid amplification of cDNA ends (3'-RACE) method. The PCR parameters included an initial denaturation at $94^{\circ} \mathrm{C}$ for $2 \mathrm{~min}$, followed by 30 cycles of denaturation at $94^{\circ} \mathrm{C}$ for $50 \mathrm{~s}$, annealing $58^{\circ} \mathrm{C}$ for $50 \mathrm{~s}$, and extension at $72^{\circ} \mathrm{C}$ for $1-3$ min depending on the sizes of the products and a final extension at $72^{\circ} \mathrm{C}$ for $10 \mathrm{~min}$. The $5 \mu \mathrm{l}$ PCR products were electrophoresed in a $0.8 \%$ agarose gel containing ethidium bromide, and visualized under UV light.

\section{Genome sequencing}

The target fragment of PCR products were purified using Gel Extraction Kit (OMEGA bio-tek). The purified products were ligated to pMD18-T vector (TaKaRa, Japan) and transfected into E. coli JM109. The positive clones were selected to provide for sequencing by Shanghai Sangon Biological Engineering Technology and Services Co., Ltd. Each nucleotide was determined from

Table 1 Synthetic oligonucleotides used for amplification of the FMDV genome ${ }^{a}$

\begin{tabular}{cccc}
\hline Primers & Position & Sequence(5'-3') & Fragment \\
\hline S1 ${ }^{\text {b }}$ & $\begin{array}{c}\text { Used for 5'- } \\
\text { RACE }\end{array}$ & CATGGCTACATGCTGACAGCCTA & 5'RACE \\
S2 & $344-367$ & TGAAAGGCGGGCGCTTGGTGACA & 5'RACE \\
U1 & $379-399$ & TAAgTITACCGTCGTTCCC & UFR \\
U2 & $718-736$ & ACCGAGCGTGGAGTCAAT & UFR \\
A1 & $524-541$ & CGGAAGTAAAACGGCACA & A \\
A2 & $2276-2293$ & GATTCCAACAGCGGTCA & A \\
B1 & $2217-2233$ & CGTGTTGGCAGCCTCAT & B \\
B2 & $4700-4717$ & CCACGGGTTCAGGTCTCG & B \\
C1 & $4576-4593$ & AACGGCCCAAGCAAGTAT & C \\
C2 & $6599-6616$ & TGGAAACGCACGAGCAGT & C \\
D1 & 6205-6222 & GGCAGAGCCATGACAGAC & D \\
D2 & $7458-7475$ & GGGTGGAAGCCAAACTCT & D \\
GSP1 & 7446-7463 & GGTGTTCGCACAGAGTT & 3'RACE \\
R1 & 3'end & TAAgCAAgCATgCCATATgTT & 3'RACE \\
3' & Used for 3'- & TAAgCAAgCATgCCATATg(T) 15 & \\
RACERT & RACE & & \\
\hline
\end{tabular}

a The primers used in this study were designed based on JS/CHA/05 (Accession NO. EF149009)

b S1 was used in 5'-RACE for amplification of the 5' end of RNA.

' 3 'RACERT was used in 3'-RACE for amplification of the 3 ' end of RNA. 
three identical results. Sequences were assembled into complete genome sequence using SeqMan I| program of DNAstar software package (DNAstar Inc., USA)

\section{Sequence comparison and phylogenetic analysis}

Ten complete genome and thirty-three VP1 gene sequences of FMDV Asial type isolates of bovine origin and three FMDV $\mathrm{O}$ type (as out group) from GenBank were involved in the analysis (Table 2). Multiple sequence comparisons at the nucleotide and the amino acid level were performed by MegAlign program of DNASTAR package. The phylogenetic tree based on VP1 sequences was constructed by using the program MEGA 4.0 [12] with Kimura 2-parameter nucleotide substitution model. The bootstrap values were determined from 1000 replicates of the original data.

\section{Putative recombination analysis}

The complete genome sequences based on the multiple alignment result were used for recombination analysis with the SimPlot program version 3.5.1[13]. Similarity plot were built using Asia1/WHN/CHA/06 as the query sequence against the complete genomic sequences of 8 strains of serotype Asia1. To further investigate the potential recombination event, the Recombination Detection Program (RDP) [14], GENECONV [15], BOOTSCAN [16], and MaxChi [17] methods were carried to employ Recombination Detection Program

Table 2 Reference FMDV strains selected from GenBank

\begin{tabular}{|c|c|c|c|c|c|c|c|}
\hline $\begin{array}{l}\text { Genbank } \\
\text { Accession no. }\end{array}$ & Strain & $\begin{array}{l}\text { Species of } \\
\text { origin }\end{array}$ & $\begin{array}{l}\text { Country and year of } \\
\text { isolation }\end{array}$ & $\begin{array}{l}\text { Genbank } \\
\text { Accession no. }\end{array}$ & Strain & $\begin{array}{l}\text { Species of } \\
\text { origin }\end{array}$ & $\begin{array}{l}\text { Country and year of } \\
\text { isolation }\end{array}$ \\
\hline FJ906802 & $\begin{array}{l}\text { WHN/ } \\
\text { CHA/06 }\end{array}$ & porcine & China, 2006 & EF187273 & $\begin{array}{l}\mathrm{HB} / \mathrm{CHA} \\
05\end{array}$ & bovine & China, 2005 \\
\hline EF149009 & JS/CHA/05 & bovine & China, 2005 & EF187272 & $\begin{array}{l}\mathrm{QH} / \\
\mathrm{CHA} / 05\end{array}$ & bovine & China, 2005 \\
\hline AY593797 & $\begin{array}{l}\text { 3kimron/ } \\
61\end{array}$ & bovine & Israel, 1963 & EF185303 & $\begin{array}{l}\mathrm{BJ} / \mathrm{CHA} / \\
05\end{array}$ & bovine & China, 2005 \\
\hline EF457988 & AFG/03 & bovine & Afghanistan, 2003 & EU091347 & MYA/06 & bovine & China, 2006 \\
\hline DQ533483 & $\begin{array}{l}\mathrm{ZB} / \mathrm{CHA} / \\
58\end{array}$ & bovine & China, 1958 & EU667461 & $\begin{array}{l}\mathrm{LAO} / 3 / \\
98\end{array}$ & bovine & Laos, 1998 \\
\hline EF149010 & $\begin{array}{l}\mathrm{HNK} / \mathrm{CHA} / \\
05\end{array}$ & bovine & Hong Kong, 2005 & FJ785294 & $\begin{array}{l}\text { IND/147/ } \\
04\end{array}$ & bovine & India, 2004 \\
\hline NC004915 & India/72 & bovine & India, 1972 & FJ785235 & $\begin{array}{l}\mathrm{HKN} / 3 / \\
05\end{array}$ & bovine & Hong Kong, 2005 \\
\hline AY687333 & $\begin{array}{l}\text { IND/321/ } \\
01\end{array}$ & bovine & India, 2001 & FJ785259 & $\begin{array}{l}\text { NKR/2/ } \\
07\end{array}$ & bovine & South Korea,2007 \\
\hline AY390432 & YNBS/58 & bovine & China, 1958 & FJ785283 & VIT/8/06 & bovine & Viet Nam, 2005 \\
\hline AY593795 & $\mathrm{PAK} / 1 / 54$ & bovine & Pakistan, 1954 & FJ785284 & VIT/1/06 & bovine & Viet Nam, 2005 \\
\hline AY593800 & LEB/83 & $?$ & Lebanon, 1983 & DQ101238 & India/04 & bovine & India,2004 \\
\hline FJ785252 & MOG/05 & bovine & Mongolia, 2005 & EU667460 & $\mathrm{Laos} / 96$ & bovine & Laos, 1996 \\
\hline FJ785240 & HKN/8/05 & bovine & Hong Kong, 2005 & FJ785268 & $\begin{array}{l}\text { Pry/RUS/ } \\
05\end{array}$ & bovine & Russia,2005 \\
\hline FJ785229 & CAM/5/97 & bovine & Cambodia, 1997 & FJ785267 & $\begin{array}{l}\text { Kha/ } \\
\text { RUS/05 }\end{array}$ & bovine & Russia, 2005 \\
\hline FJ785290 & VIT/4/06 & water buffalo & Viet Nam, 2005 & FJ785266 & $\begin{array}{l}\text { PAK/22/ } \\
05\end{array}$ & bovine & Pakistan, 2005 \\
\hline DQ101242 & India/02 & bovine & Afghanistan, 2001 & FJ785228 & $\begin{array}{l}\text { CAM/9/ } \\
80\end{array}$ & $?$ & Cambodia, 1980 \\
\hline FJ785227 & AFG/3//01 & bovine & Afghanistan, 2001 & FJ785249 & $\begin{array}{l}\mathrm{KRG} / 2 / \\
04\end{array}$ & $?$ & Kyrgyzstan, 2004 \\
\hline FJ785246 & IRN/30/04 & $?$ & Iran, 2004 & DQ121116 & IND/80 & $?$ & India,1980 \\
\hline FJ785258 & MYA/1/05 & $?$ & Myanmar,2005 & DQ121117 & India/81 & $?$ & India, 1981 \\
\hline FJ785277 & UZB/2003 & $?$ & Uzbekistan, 2003 & AF308157 & O/TW/97 & porcine & Taiwan, 2002 \\
\hline DQ121401 & Russia/05 & $?$ & Russia, 2005 & AY317098 & $\begin{array}{l}\mathrm{O} / \mathrm{HKN} / \\
02\end{array}$ & $?$ & Hong Kong, 2002 \\
\hline EF185304 & GS/CHA/05 & bovine & China, 2005 & AY312589 & $\begin{array}{l}\text { O/SKR/ } \\
02\end{array}$ & porcine & South Korea,2002 \\
\hline
\end{tabular}

\footnotetext{
${ }^{a}$ Eleven completely sequenced FMDV strains are indicated in boldface.

${ }^{\mathrm{b}}$ Question mark (?) indicates that data is inadequate.

${ }^{\mathrm{C}} \mathrm{All}$ the reference strains, except O/TW/97, O/HKN/02, and O/SKR/02, are FMDV serotype Asia1.
} 
3 (RDP3) [18] software. Statistical significance was set at the $\mathrm{P}=0.05$ level. Each analysis was conducted twice to ensure repeatability of results.

\section{Results}

Virus isolation and identification

Virus from one sample was adapted to BHK-21 cells and CPE occurred when inoculated fresh cultures first time after 24 hours, but the other two didn't show any CPE by blind passage 5 times. Therefore, one strain of virus was isolated, and the first passage of the strain in BHK cells was used for following experiments. For complement fixation test, hemolysis occurred in the mixtures containing FMDV $\mathrm{O}$ and A type positive serums, whereas the mixtures containing FMDV Asia1 type positive serums didn't show any virtual change. Thus, the isolate was identified as FMDV of serotype Asia1, and was designated as Asia1/WHN/CHA/06.

\section{RT-PCR and complete genome of Asia1/WHN/CHA/06}

In order to determine the full-length genome sequence of Asia1/WHN/CHA/06 strain, the seven RT-PCR cDNA amplicons covering the entire RNA genome were cloned and each nucleotide was determined from three identical results. The genome sequence was submitted to GenBank with the accession number of FJ906802. The complete genome sequence of Asia1/WHN/CHA/06, excluding poly $(\mathrm{C})$ and poly $(\mathrm{A})$ tail, is $8161 \mathrm{nt}$ in length, containing an ORF, a 5' UTR, and a 3' UTR. ORF is 6990 nt (encoding 2329 aa)in length, which consists of L (603 nt), P1 (2199 nt), P2 (1464 nt), and P3 (2724 nt) genes. P1 protein is predicted to be cleaved into four structural proteins, including VP4 (85 aa), VP2 (219 aa), VP3 (218 aa), and VP1 (211 aa). There are three non-structural proteins in P2, including 2A (16 aa), 2B (154 aa), and 2C (318 aa). P3 protein contains 3A (153 aa), 3B (71 aa), 3C (213 aa), and 3D (471 aa) four proteins. The 5' UTR consists of S, FUR, and IRES structures, which is 366, 258, and $454 \mathrm{nt}$ in length, respectively. The 3' UTR of Asia1/ WHN/CHA/06 was $93 \mathrm{nt}$ in length, followed by a $66 \mathrm{bp}$ poly (A) tail at least.

\section{Sequence analysis}

Nucleotide and amino acid identity of different regions of Asia1/WHN/CHA/06 genome were compared with other six FMDV Asia1 strains (Table 3). Asia1/WHN/ CHA/06 genome exhibited identities ranging from 90.2 to $98.5 \%$, and the highest similarity with JS/CHA/05 with identity rate of $98.5 \%$.

The ORF of Asia1/WHN/CHA/06 was 89.6 - 98.5\% identical with the six reference sequences at the nucleotide level with no deletion or insertion. Compared with 40 sequences of VP1 genes, Asia1/WHN/CHA/06 exhibited identities ranging from 81.0 to $99.2 \%$ (data not shown). By comparing the 40 amino acid sequences of G-H loop region in VP1 protein, Asia1/WHN/CHA/06 got highly consistency with the stains isolated after the year of 2004, and no mutation was observed in RGD tripeptide. Interestingly, RGD mutants (RGD $\rightarrow$ HGD) were examined in Asia1/3kimron/61 and KRG/2/04. For bordering region of RGD of Asia1/WHN/CHA/06, there was no amino acids' mutation at RGD +1 and +4 sides, but a mutation at the RGD $+9(\mathrm{~N} \rightarrow \mathrm{D})$. The $3 \mathrm{~A}$ gene of Asia1/WHN/CHA/06 strain was 459 nt without insertions and deletions at this region. However, three amino acids' mutations occurred at the residues $86(\mathrm{D} \rightarrow \mathrm{N}), 93$ $(\mathrm{I} \rightarrow \mathrm{N})$, and $131(\mathrm{H} \rightarrow \mathrm{R})$. Interestingly, Asia1/WHN/ CHA/06 displayed the highest nucleotide similarity with JS/CHA/05 at all the regions except 3B gene (93.4\%), whereas it showed the highest similarity $(97.7 \%)$ with HNK/CHA/05 at 3B gene.

The 5' UTR of Asia1/WHN/CHA/06 shared 96.8\% identity with the JS/CHA/05 strain, whereas it showed only 84.4-86.7\% identity with other 5 reference strains. For the S fragment of 5'UTR, Asia1/WHN/CHA/06 displayed 3 nucleotide deletions located at nt 72, 74, and 184. The 712-nt of Asia1/WHN/CHA/06 of 5' LF-UTRs was observed, whereas within other reference strains, the length of 5' LF-UTRs ranged from 690 nts to 714 nts. Asia1/WHN/CHA/06 strain showed four PKs structure in 5' LF-UTR, which was the same as other reference isolates, and no nucleotide deletion was observed. For the IRES fragment of 5' UTR, Asia1/WHN/CHA/06 was more genetic conservative than that of $\mathrm{S}$ fragment, displaying 86.8-99.3\% homology to other Asia1 type isolates, and only found to be 2 nucleotide deletions. The sequence comparison of the 3' UTR regions showed that Asia1/ WHN/CHA/06 exhibited 74.2-87.1\% homology to other six Asia1 type isolates, indicating a relatively higher level of genetic variation within the 3' UTR than the 5'UTR.

\section{Phylogenetic analysis}

Phylogenetic trees were constructed based on the sequence alignment of VP1 gene of 39 FMDV strains. In the phylogenetic tree, FMDV Asia1 type strains were distributed into three different groups (Figure 1). Group1 fell into two distinct groups (1a and 1b). Asia1/WHN/CHA/ 06 was distributed into group1a with India/80, India/81, and other 10 isolates during 2005-2007 from East Asia. Group 1b was made up of YNBS/58 and ZB/CHA/58, which were both isolated from China in 1958. Group2 contained the isolates from India, Central Asia, and Hong Kong in 1983-2005. And group3 was exclusively formed by Southeast Asia strains from 1980 to 2006.

\section{Recombination analysis}

In the similarity plot, Asia1/WHN/CHA/06 was shown to be closer to JS/CHA/05 than the other 8 strains. 
Table 3 Similarity comparison of nucleotide and amino acid sequences of Asia1/WHN/CHA/06 to other FMDV Asia1 type isolates

\begin{tabular}{cllllll}
\hline Asia1/WHN/CHA/06 & \multicolumn{7}{l}{ Nucleotide (amino acid) sequence similarity (\%) with Asia1/WHN/CHA/06 } & \\
\cline { 2 - 6 } & JS/CHA/05 & ZB/CHA/58 & HNK/CHA/05 & IND/321/01 & YNBS/58 & PAK/1/54 \\
\hline 5'UTR & 96.8 & 86.3 & 84.0 & 86.7 & 85.8 & 84.4 \\
S & 95.1 & 83.3 & 77.9 & 83.3 & 83.3 & 78.7 \\
5'LF-UTR & 98.3 & 88.5 & 87.8 & 89.0 & 89.0 & 88.1 \\
FUR & 96.5 & 87.6 & 88.4 & 89.9 & 88.4 & 88.8 \\
IRES & 99.3 & 89.4 & 89.0 & 89.0 & 86.8 & 88.5 \\
ORF & $98.5(97.7)$ & $89.8(94.9)$ & $89.7(95.7)$ & $89.6(95.5)$ & $89.7(95.1)$ & $89.6(96.3)$ \\
L & $98.3(98.5)$ & $84.2(90.0)$ & $87.7(95.0)$ & $86.2(92.5)$ & $83.9(89.6)$ & $86.7(96.0)$ \\
VP4 & $99.2(100.0)$ & $89.8(97.6)$ & $91.8(100.0)$ & $90.2(100.0)$ & $89.0(96.5)$ & $92.2(98.8)$ \\
VP2 & $98.9(98.6)$ & $87.4(92.7)$ & $87.4(95.0)$ & $86.1(94.5)$ & $87.5(93.2)$ & $86.5(95.4)$ \\
VP3 & $99.7(100.0)$ & $88.8(95.9)$ & $86.9(96.8)$ & $84.4(96.3)$ & $88.5(95.9)$ & $87.2(96.8)$ \\
VP1 & $98.9(99.1)$ & $85.5(93.4)$ & $82.1(89.6)$ & $81.4(87.7)$ & $84.2(91.5)$ & $84.0(87.7)$ \\
2A & $100.0(100.0)$ & $83.3(93.8)$ & $95.8(100.0)$ & $89.6(100.0)$ & $85.6(100.0)$ & $95.8(100.0)$ \\
2B & $98.5(98.7)$ & $93.3(96.1)$ & $93.3(96.8)$ & $94.4(97.4)$ & $94.2(97.4)$ & $91.3(98.7)$ \\
2C & $96.6(97.2)$ & $93.1(97.2)$ & $91.7(95.9)$ & $93.1(96.9)$ & $92.3(95.9)$ & $92.6(97.2)$ \\
3A & $98.7(98.0)$ & $89.1(89.5)$ & $89.5(93.5)$ & $91.3(94.1)$ & $90.8(92.8)$ & $88.9(92.8)$ \\
3B & $93.4(95.8)$ & $92.5(93.0)$ & $97.7(100.0)$ & $93.4(97.2)$ & $92.5(93.0)$ & $93.4(98.6)$ \\
3C & $97.5(99.5)$ & $90.1(97.2)$ & $92.5(97.7)$ & $92.5(97.7)$ & $90.1(96.7)$ & $90.6(98.6)$ \\
3D & $99.1(99.1)$ & $93.2(98.1)$ & $93.5(98.1)$ & $92.6(97.0)$ & $93.0(98.1)$ & $93.1(98.1)$ \\
3'UTR & 87.1 & 81.7 & 87.1 & 74.2 & 96.3 & 87.1 \\
Complete & 98.5 & 90.5 & 90.3 & 90.2 & 90.5 & 90.3 \\
\hline
\end{tabular}

${ }^{a}$ The interests of the names of the fragments and data are indicated in boldface.

${ }^{b}$ Similarity rates of amino acid are shown in brackets.

However, there were two narrow zones displaying disproportionately low levels of similarity between the two strains compared to the other regions (Figure 2). Moreover, Asia1/WHN/CHA/06 was shown to have a higher similarity to HNK/CHA/05 than JS/CHA/05 within the right narrow zone (corresponding to $3 \mathrm{~B} / 3 \mathrm{C}$ ), which suggested that there was a possible recombination event in this region. And it was shown that the major parent was JS/CHA/05, and the minor parent was HNK/CHA/05. In the analysis by RDP program, the segment corresponding to $3 \mathrm{~B} / 3 \mathrm{C}$ region was defined as a crossover region (Figure 3,4), which indicated that JS/CHA/05 and HNK/CHA/05 were possible mosaics with Asia1/ WHN/CHA/06. And the estimated recombination breakpoint was at the position 5805-6073.

\section{Disscusion}

Asia1/WHN/CHA/06 was isolated from pigs in a pig farm in 2006. According to the investigation of the pig farm during the outbreak, about $20 \%$ of sows presented typical clinical symptoms of FMD, whereas none of the piglets and boars showed any symptoms and no pigs died. The FMD in the pig farm lasted for about one month. Moreover, there were not any reports about outbreak of FMD in other pig farms around the area at that time. Therefore, we speculated that Asia1/WHN/CHA/
06 had low pathogenicity or infectivity to pigs, though high lethality of the strain to sulking mouth was observed in this study. But further study should be carried out to test the virulence of the strain to pigs to approve the inference.

The complete genome sequence of Asia1/WHN/CHA/ 06 was determined, except Poly $(C)$ tract. Poly $(C)$ tract of FMDV is usually ranging from 100 to 420 cytosine residues interspersed with an occasional uracil residue [19], so it is difficult to amplify the true sequence of the tract by RT-PCR from the viral RNA genome [20]. In this study, we didn't manage to get the poly $(\mathrm{C})$ tract sequence of Asia1/WHN/CHA/06 either. Pseudoknots (PKs) have been found to be 3-4 tandem repeats of RNA secondary structure in FMDV genome, which probably had some role during viral replication [21]. Additionally, it is reported that partial deletions of FMDV strains in PKs' region correlated with the host range [22]. However, no deletions occurred in PKs' region of Asia1/WHN/CHA/06. In sequence of VP1 protein, the RGD motif is the molecular basis of binding of FMDV to its cellular receptor [23]. Although the RGD bordering region sequence of Asia1/WHN/CHA/ 06 is highly consistent with the reference strains isolated after the year of 2004, an amino acids' position at RGD +9 mutated $(\mathrm{N} \rightarrow \mathrm{D})$. As several lines of evidence show 


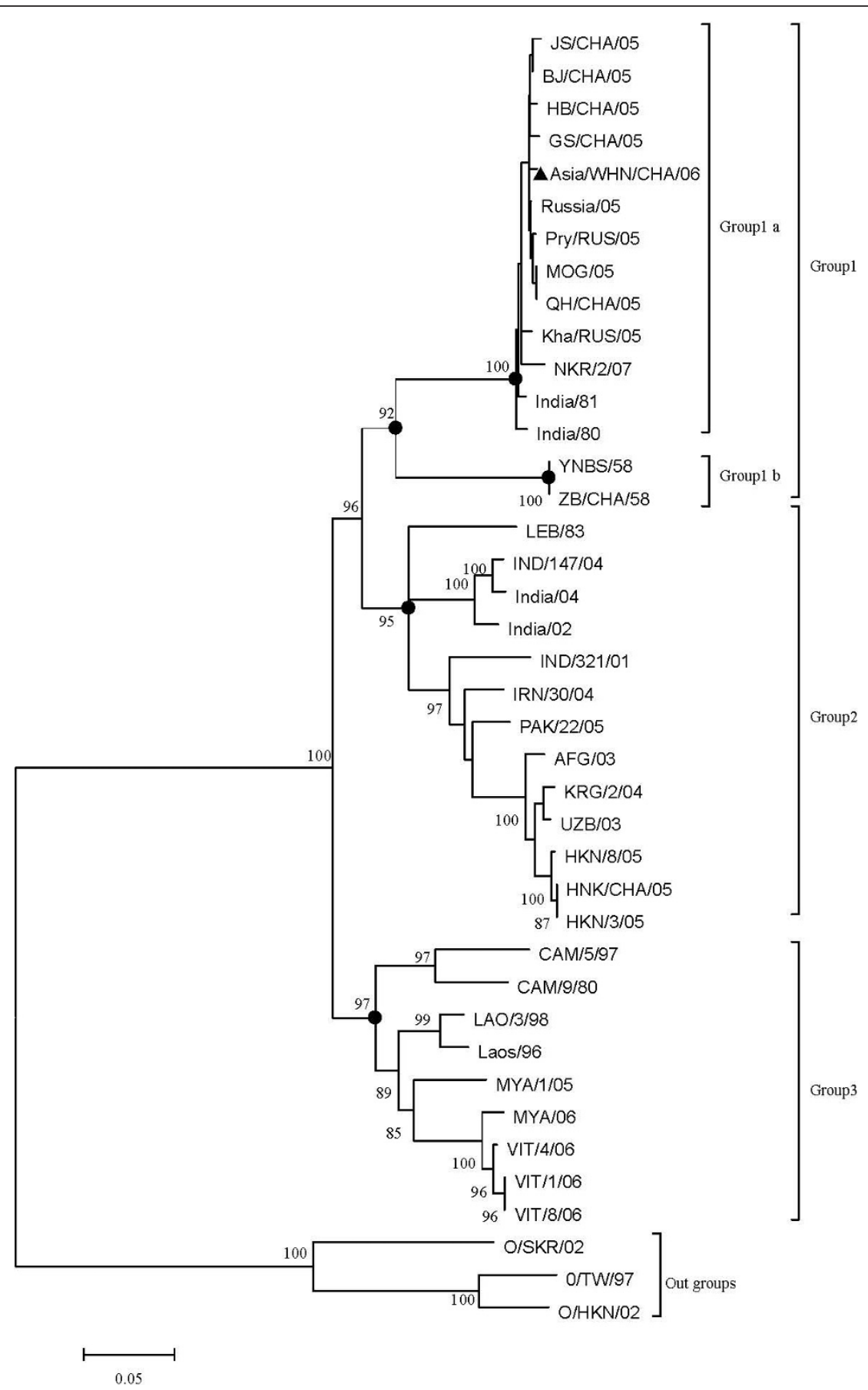

Figure 1 Phylogenetic tree based on VP1 gene sequences of Asia1/WHN/CHA/06 and selected 36 reference strains. Three sequences of VP1 gene of type O FMDV were used as outgroups.

that the vicinity of the RGD motif, including RGD +1 (leucine) and +4 (leucine) positions, are necessary for the FMDV RGD-mediated receptor recognition $[24,25]$, it is unclear whether the variation at RGD +9 site influence the receptor recognition of Asia1/WHN/CHA/06. Although non-structural proteins which play important roles for viral propagation are generally more conserved than the structural proteins, $3 \mathrm{~A}$ is one of the most variable proteins of FMDV [11]. In addition, deletions in 3A have been shown to associate with FMDV attenuation in cattle and high virulence for pigs [21]. Meanwhile, a single amino acid mutation at position 44 in the $3 \mathrm{~A}$ 


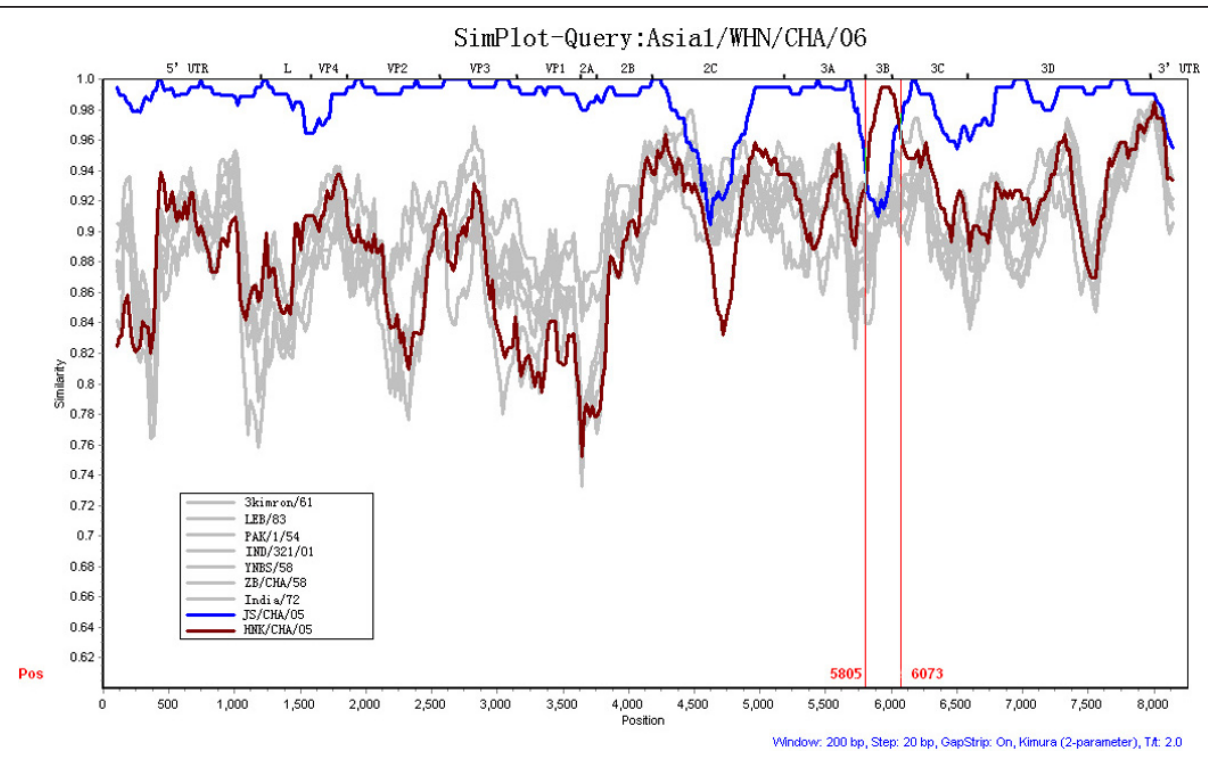

Figure 2 Nucleotide similarity comparison of the complete sequences of Asia1/WHN/CHA/06 with those of representative FMDVs. It showed a window size of $200 \mathrm{nt}$ and a step size of $20 \mathrm{nt}$. The $x$-axis indicates nucleotide positions along the alignment and the $y$-axis denotes the similarity. The vertical lines show the recombination points at position 5805 and 6073.

protein is present in guinea pig-adapted isolates examined [26]. In our study, we found no deletion but 3 amino acid substitutions in the $3 \mathrm{~A}$ region of Asia1/ WHN/CHA/06. Considering that the isolate isolated from a pig, while other FMDV Asia1 type isolates came from cattle, it would be interesting to examine by reverse genetics if the 3 amino acid substitutions may contribute to adaptation of host range.

From a practical point of view, it is important to analyze the nucleotide sequence of the virus from new hosts for subsequent comparison with other isolates to trace the origin and route of the viral spread. To date, there are over 40 complete genome sequences for FMDV Asia1 isolated from cattle available in Genbank, but no data are available on pigs. The present study reported that the complete nucleotide sequence of Asia1/WHN/CHA/06 was isolated from pigs in southwest of China in 2006. In general, the complete genome sequence of Asia1/WHN/CHA/06 exhibited a high level of similarity with JS/CHA/05 strain, which indicated that Asia1/WHN/CHA/06 had a close genetic relationship with JS/CHA/05 strain. Phylogenetic analysis of the virus VP1 region of FMDV has been used extensively to investigate the molecular epidemiology of the disease worldwide [27]. In this study, phylogenetic tree based on VP1 region of Asia1 isolates identified the existence of three groups. Group1a mainly consisted of 11 isolates, which collected in East Asia (China, East of Russia,

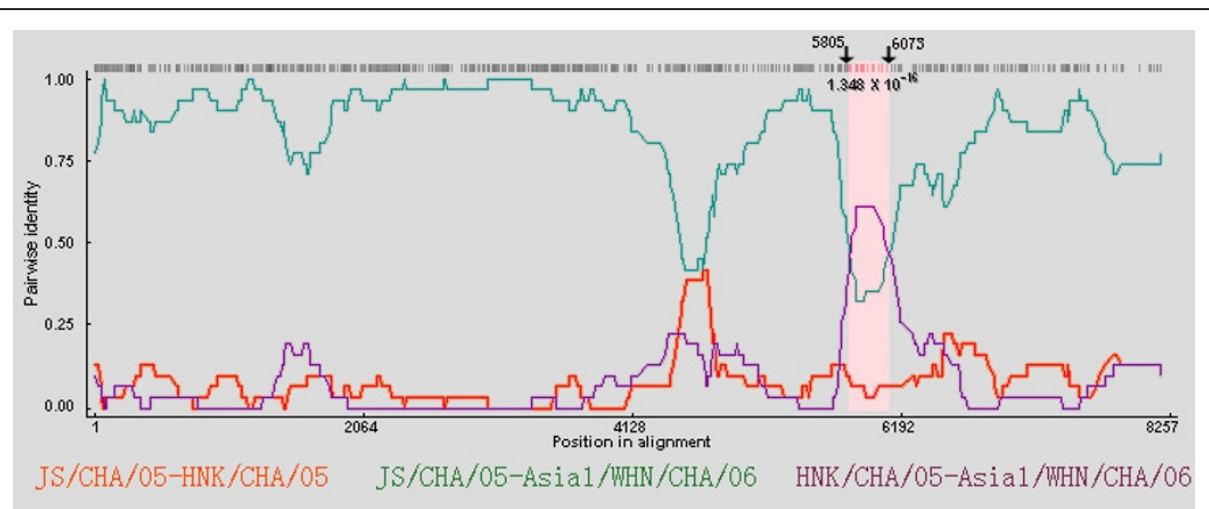

Figure 3 RDP screenshots displaying the possible recombination events associated with Asia1/WHN/CHA/06. The $y$-axis indicates the pairwise identity that refers to the average pairwise sequence identity within a 30nt sliding window moved one nucleotide at a time. The area outlined in pink demarcates the potential recombination regions. Crossover sites were indicated by arrows with nt positions above. 


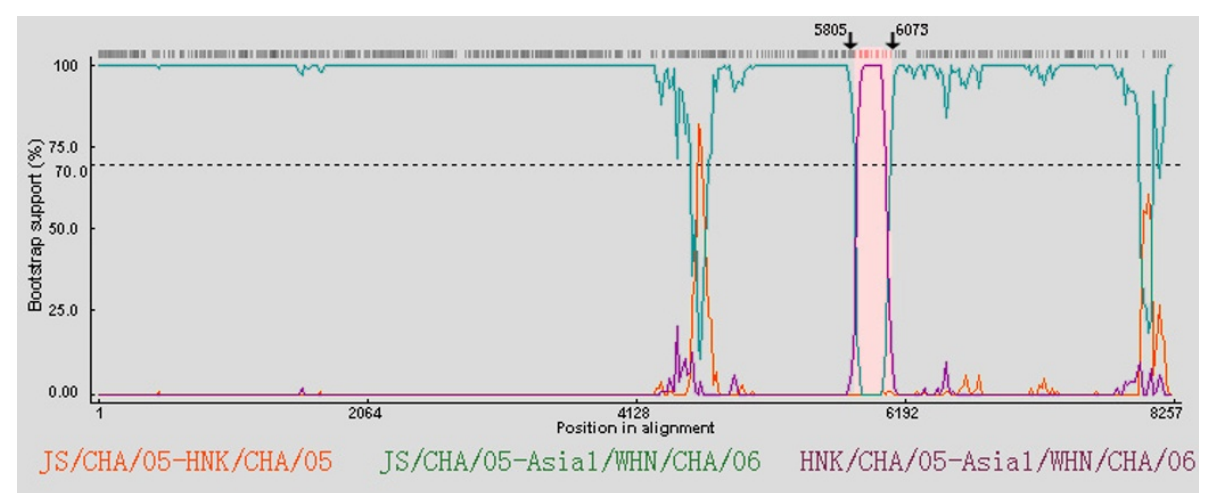

Figure 4 Bootscan plots showing the likehood of recombinant sequence (Asia1/WHN/CHA/06) with JS/CHA/05 and HNK/CHA/05. The $y$ axis indicates the percentage of bootstrap values that support the clustering of Asia1/WHN/CHA/06 with the parental strains. Boot strap values over $70 \%$ are considered significant. The area outlined in pink demarcates the potential recombination regions. Crossover sites were indicated by arrows with nt positions above.

East of Mongolia, and North Korea) during 2005-2007. However, India/80 and India/81, which were both collected from India in 1980s, also clustered with Group1a. These data suggest that the East Asia strains, including Asia1/WHN/CHA/06, have a close genetic relationship with the two India strains emerged two decades ago.

Recombination plays an important role in FMDV evolution $[28,29]$. In this study, supported by Simplot and RDP program, Asia1/WHN/CHA/06 was found to be a mosaic between JS/CHA/05 and HNK/CHA/05, whose breakpoint encompassed partial $3 \mathrm{~B}$ and $3 \mathrm{C}$ genes. Protein $3 \mathrm{~B}$, which is present in three similar but nonidentical copies $\left(3 \mathrm{~B}_{1}, 3 \mathrm{~B}_{2}\right.$ and $\left.3 \mathrm{~B}_{3}\right)$ in FMDV [30], functions in priming picornavirus RNA synthesis [31], and the $3 \mathrm{C}$ protease is responsible for most of the cleavages during the FMDV polyprotein processing [32]. Recombination in FMDV occurs mainly in non-structural genes [33], but the recombination over $3 \mathrm{~B} / 3 \mathrm{C}$ gene boundaries appears to be less frequent [34]. Thus, the role of the mosaicism observed in 3B/3C of FMDV should be targeted for further study. Moreover, JS/CHA/05 and HNK/CHA/05 strains were both isolated from the east of China in 2005, so there was a geographical opportunity for the recombination of the two strains. However, as Asia1/WHN/CHA/06 was isolated from west of China, it was possible that Asia1/WHN/CHA/06 was transmitted from east of China by introduction of pigs or other transmission routes.

\section{Conclusion}

Here we reported, for the first time to our knowledge, the isolation and identification of a strain of FMDV type Asia1 from naturally infected pigs, and described the features of the genome of Asia1/WHN/CHA/06. Sequence analysis showed that it was belonged to
East Asian strains, and had a close genetic relationship to JS/CHA/05. Besides, potential recombination events associated with Asia1/WHN/CHA/06 were found between JS/CHA/05 and HNK/CHA/05 strains with partial $3 \mathrm{~B}$ and $3 \mathrm{C}$ fragments, which may trace the origin and evolution of Asia1/WHN/CHA/06 strain.

\section{Acknowledgements}

This research was supported by China National '11th Five-Year Plan' Science and Technology Supporting Program: Research and Demonstration for Healthy Breeding of new model in intensive pig farms (2006BAD14B05).

\section{Authors' contributions}

All authors participated in the planning of the project. HNW was the leader of the project. XY and YSZ carried to the complete genome, virus isolation and identification, phylogenetic analysis and draft of the manuscript. $Y Z$ and KW participated in phylogenetic analysis and recombination analysis. TW participated in the collection of the clinical samples. All authors read and approved the final manuscript.

\section{Competing interests}

The authors declare that they have no competing interests.

Received: 18 February 2011 Accepted: 16 April 2011

Published: 16 April 2011

\section{References}

Domingo, E, C Escarmis, E Baranowski, CM Ruiz-Jarabo, E Carrillo, Jl Nunez, and F Sobrino. 2003. Evolution of foot-and-mouth disease virus. Virus Res 91: 47-63. doi:10.1016/S0168-1702(02)00259-9.

Zhang, Q, D Li, X Liu, Z Liu, X Cai, G Wu, S Qi, S Yang, X Yan, Y Shang, J He, J Ma, J Li, W Ma, R Han, X Liu, J Zhang, Q Xie, and Z Zhang. 2008. Experimental studies with foot-and-mouth disease virus type Asia-1, responsible for the 2005 epidemic in China. Res Vet Sci 85: 368-371. doi:10.1016/j.rvsc.2007.11.005.

Lau, LT, SM Reid, DP King, AMF Lau, AE Shaw, NP Ferris, and ACH Yu. 2008. Detection of foot-and-mouth disease virus by nucleic acid sequence-based amplification. Vet Microb 126: 101-110. doi:10.1016/j.vetmic.2007.07.008.

Grubman, MJ, and B Baxt. 2004. Foot-and-mouth disease. Clin Microb 17: 465-493. doi:10.1128/CMR.17.2.465-493.2004.

Belsham, GJ. 2005. Translation and replication of FMDV RNA. Curr T Micr 288: 43-70. doiffull_text. 
Du, J, H Chang, G Cong, J Shao, T Lin, Y Shang, Z Liu, X Liu, X Cai, and Q Xie. 2007. Complete nucleotide sequence of a Chinese serotype Asia1 vaccine strain of foot-and-mouth disease virus. Virus Genes 35: 635-642. doi:10.1007/ s11262-007-0126-8.

Malirat, V, de Barros JJF, IE Bergmann, RM Campos, E Neitzert, VC Eliane, EE Da Silva, AJ Falczuk, DSB Pinheiro, V Natalia, LQC Jose, M Eduardo, and DL Rosa. 2007. Phylogenetic analysis of foot-and-mouth disease virus type $\mathrm{O}$ reemerging in free areas of South America. Virus Res 124: 22-28. doi:10.1016/j. virusres.2006.09.006.

Brown, F, N Benkirane, D Limal, H Halimi, JFE Newman, MHV Regenmortel, JP Briand, and S Muller. 2008. Delineation of a neutralizing subregion within the immunodominant epitope (GH loop) of foot-and-mouth disease virus VP1 which does not contain the RGD motif. Vaccine 18: 50-56. doi:10.1016/ S0264-410X(99)00169-3.

Lama, J, MA Sanz, and L Carrasco. 1998. Genetic analysis of poliovirus protein 3A: characterization of a non-cytopathic mutant virus defective in killing Vero cells. J Gen Virol 79: 1911-1921.

Domingo, E, E Baranowski, C Escarmis, and F Sobrino. 2002. Foot-and-mouth disease virus. Comp Immu M I 25: 297-308.

Carrillo, C, ER Tulman, G Delhon, Z Lu, A Carreno, A Vagnozzi, GF Kutish, and DL Rock. 2005. Comparative genomics of foot-and-mouth disease virus. J Virol 79: 6487-6504. doi:10.1128/JVI.79.10.6487-6504.2005.

Tamura, K, J Dudley, M Nei, and S Kumar. 2007. MEGA4: molecular evolutionary genetics analysis (MEGA) software version 4.0. Mol Biol Ev 24: 1596-1599. doi:10.1093/molbev/msm092.

Lole, KS, RC Bollinger, RS Paranjape, D Gadkari, SS Kulkarni, NG Novak, R Ingersoll, HW Sheppard, and SC Ray. 1999. Full-length human immunodeficiency virus type 1 genomes from subtype C-infected seroconverters in India, with evidence of intersubtype recombination. J Virol 73(1): 152-160.

Martin, DP, and E Rybicki. 2000. RDP: detection of recombination amongst aligned sequences. Bioinformatics 16: 562-563. doi:10.1093/bioinformatics/ 16.6.562.

Padidam, M, S Sawyer, and CM Fauquet. 1999. Possible emergence of new geminiviruses by frequent recombination. Virology 265: 218-225. doi:10.1006/ viro.1999.0056.

Martin, DP, D Posada, KA Crandall, and C Williamson. 2005. A modified BOOTSCAN algorithm for automated identification of recombinant sequences and recombination breakpoints. AIDS Res Hum Retroviruses 21: 98-102. doi:10.1089/aid.2005.21.98.

Smith, JM. 1992. Analyzing the mosaic structure of genes. J Mol Evol 34: 126-129.

Heath, L, E Walt, A Varsani, and DP Martin. 2006. Recombination patterns in aphthoviruses mirror those found in other picornaviruses. J Virol 80: 11827-11832. doi:10.1128/JVI.01100-06.

Escarmis, C, M Toja, M Medina, and E Domingo. 1992. Modification of the 5' untranslated region of foot-and-mouth disease virus after prolonged persistence in cell culture. Virus Res 26: 113-125. doi:10.1016/0168-1702(92) 90151-X.

Rieder, E, T Bunch, F Brown, and PW Mason. 1993. Genetically engineered footand-mouth disease viruses with poly $(C)$ tracts of two nucleotides are virulent in mice. J Virol 67: 5139-5145.

Biswas, S, A Sanyal, D Hemadri, C Tosh, JK Mohapatra, KR Manoj, and SK Bandyopadhyay. 2006. Sequence analysis of the non-structural 3A and 3C protein-coding regions of foot-and-mouth disease virus serotype Asia1 field isolates from an endemic country. Vet Microb 116: 187-193. doi:10.1016/j.vetmic.2006.03.001.

Dunn, CS, and Al Donaldson. 1997. Natural adaption to pigs of a Taiwanese isolate of foot-and-mouth disease virus. Vet Rec 141: 174-175. doi:10.1136/ vr.141.7.174.

Storey, P, J Theron, FF Maree, and HG O'Neill. 2007. A second RGD motif in the 1D capsid protein of a SAT1 type foot-and-mouth disease virus field isolate is not essential for attachment to target cells. Virus Res 124: 184-192. doi:10.1016/j.virusres.2006.11.003.

Jackson, T, W Blakemore, JWI Newman, NJ Knowles, AP Mould, MJ Humphries, and AMQ King. 2000. Foot-and-mouth disease virus is a ligand for the highaffinity binding conformation of integrina $5 \beta 1$ : influence of the leucine residue within the RGDL motif on selectivity of integrin binding. J Gen Virol 81: 1383-1391.

Jackson, T, AP Mould, D Sheppard, and AMQ King. 2002. Integrin av $\beta 1$ is a receptor for foot-and-mouth disease virus. J Virol 76: 935-941. doi:10.1128/ JVI.76.3.935-941.2002.
Nunez, Jl, E Baranowski, N Molina, CM Ruiz-Jarabo, C Sanchez, E Domingo, and F Sobrino. 2001. A single amino acid substitution in non-structural protein 3A can mediate adaptation of foot-and-mouth disease virus to the guinea pig. J Virol 75: 3977-3983. doi:10.1128/JVI.75.8.3977-3983.2001.

Ayelet, G, M Mahapatra, E Gelaye, BG Egziabher, T Rufeal, M Sahle, NP Ferris, J Wadsworth, GH Hutchings, and NJ Knowles. 2009. Genetic Characterization of Foot-and-Mouth Disease Viruses, Ethiopia, 1981-2007. Em Infect D 15: 1409-1417. doi:10.3201/eid1509.090091.

Haydon, DT, AD Bastos, and P Awadalla. 2004. Low linkage disequilibrium indicative of recombination in foot-and-mouth disease virus gene sequence alignments. J Gen Virol 85: 1095-1100. doi:10.1099/vir.0.19588-0.

Rensburg, HG, D Haydon, F Joubert, AD Bastos, L Heath, and L Nel. 2002. Genetic heterogeneity in the foot-and-mouth disease virus Leader and $3 \mathrm{C}$ proteinases. Gene 289: 19-29. doi:10.1016/S0378-1119(02)00471-7.

Forss, S, and H Schaller. 1982. A tandem repeat gene in a picornavirus. Nucleic Acids Res 10: 6441-6450. doi:10.1093/nar/10.20.6441.

Wimmer, E. 1982. Genome-linked proteins of viruses. Cell 28: 199-201. doi:10.1016/0092-8674(82)90335-X.

Vakharia, VN, MA Devaney, DM Moore, JJ Dunn, and MJ Grubman. 1987. Proteolytic processing of foot-and-mouth disease virus polyproteins expressed in a cell-free system from clone-derived transcripts. J Virol 61: 3199-3207.

Klein, J, M Hussain, M Ahmad, P Normann, M Afzal, and S Alexandersen. 2007. Genetic characterisation of the recent foot-and-mouth disease virus subtype A/IRN/2005. Virol J 4: 122. doi:10.1186/1743-422X-4-122.

Jackson, AL, H O'Neill, F Maree, B Blignaut, C Carrillo, L Rodriguez, and DT Haydon. 2007. Mosaic structure of foot-and-mouth disease virus genomes. J Gen Virol 88: 487-492. doi:10.1099/vir.0.82555-0.

doi:10.1186/1743-422X-8-175

Cite this article as: Yang et al:: Isolation, identification and complete genome sequence analysis of a strain of foot-and-mouth disease virus serotype Asia1 from pigs in southwest of China. Virology Journal 2011 8:175.

\section{Submit your next manuscript to BioMed Central and take full advantage of:}

- Convenient online submission

- Thorough peer review

- No space constraints or color figure charges

- Immediate publication on acceptance

- Inclusion in PubMed, CAS, Scopus and Google Scholar

- Research which is freely available for redistribution 